\title{
Influence of Gadget Usage on Children's Social-Emotional Development
}

\author{
Mildayani Suhana \\ Universitas Pendidikan Indonesia \\ Bandung,Indonesia \\ milda@student.upi.edu
}

\begin{abstract}
Gadget is part of ICT which is mostly used. One effect of gadget usage on children is self isolated from social life and lack of emotional management. It is resulted in lack of interaction and communication. Child become introvert and impatient, interpersonal problem and lack of interpersonal communication skill and keep them away from nature and surrounding environment. This paper reports based on literature review on how many parents are proud if they had bough expensive and sophisticated gadget for their children. This problem need to be studied because many children nowadays spend more time playing with gadget than playing with their peers and neighbors who can give socialization and emotional management experience. With various advantage and disadvantage of gadget, parents should be careful and wise in giving tool and facility which are suitable with their children needs to support children development. The conclusion lies in the role of parents in understanding the needs of children.
\end{abstract}

Keywords: gadget; social-emotional; children

\section{INTRODUCTION}

Human is social creature who is interact and communicate with another human [1]. With era and technology development, human create system and tool which can facilitate human when they communicate with human fellows. The advance of telecommunication such as telephone, radio, and television had made a change in individual or community. Most media sources related to children make them to become passive user, but with the advance of technology nowadays enable children to interact actively with technical device available and children are adapted faster with that.However, the information communication and technology (ICT) which is increasingly developed bring negative effect in gadget usage if it is used excessively [2]. The phenomena shows that each individual has familiar and use gadget with sophisticated feature and application which attract its users.

According to Child Development expert, Lencana Mastura (Dr.), that addiction to iPad, tablet and another devices usage is so widespread among children and it is the main challenge faced by parents to educate their children and concern them in globalization era. The life of preschool children in modern era is very influenced by electronic media. Dallea, Mutalibb, Saadb, Ayubc, Wahabc, and Nasrallad said that as the effect of electronic media, children have less space to participate in real world. Based on some studies, children aged 0-2 years old should not exposed to gadget, children aged 3-5 years old are limited only 1 hour per day, and 2 hours per day for children aged 6-18 years old [3]. But the fact in field shows that many children who use gadget 4 5 times more than the amount recommended.

In reality, gadget play supporting role in the lifestyle nowadays. Based on data from KOMINFO in 2014, the rate of gadget usage in Indonesia is very high. Based on survey, it is found that 98 percent of children and adolescents in Indonesia know about internet and 79.5 percent among them are internet users. Children who are frequently use technology often ignore their surrounding environment. They prefer facing sophisticated technology they have than playing with their peers in playground or in environment surrounding them. So social communication between children and environment is increasingly reduced.

According to Upadhyay, Jesudass and Chitale, one effect of gadget usage is forgetting social life. As a result, they are lack in interaction and communication because they become introvert and impatient [4]. Bhattacharya stated that the effect of gadget usage excessively will raise interpersonal and communication skill problem in children and it will take them away from nature and surrounding environment [5]. This situation can change their behavior and they will self withdraw from social life [6] and can reduce their level of creativity. Whereas, the main aspect in children development and education particularly in early age is social skill development, emotional aspect of social-spiritual value application and enhancement.

The sophistication of communication device which give convenience to people is aninevitable challenge, but how we can utilize communication 
device as vehicle to make the work easier [1]. The phenomena occurs today is parents intentionally give gadget to their children since early age in order to monitor them when they are far from home and they not worrying their children when they work outside. But parents' attitude tend to allow their children to use gadget freely without supervision and control. Whereas, technology also enable parents to control and monitor communication device usage and the content of gadget for children. Parents are demanded to more knowledgeable about the advance of this technology and always control and supervise their children when using that technology.

Based on literature, the researcher want to know the influence of gadget usage on children's social and emotional development and parent role in gadget usage among children. Because the fact in field showed that parents intentionally introduce gadget since early age to children without considering the effect invoked from it.

\section{DISCUSSION}

\section{THE INFLUENCE OF GADGET USAGE ON CHILDREN'S SOCIAL DEVELOPMENT}

With its capacity and accessibility, ICT has attraction for its users [2]. One of them is gadget with all easiness and sophistication contained in it make the users including children become addicted. The high curiosity make children continuously use gadget in the long time. Children should learn more from face to face interaction than a screen. They see someone who is able to that as true learning partner. They do not have way to know whether the character or face in screen is really understand them.

Childhood is the period of aspects development including their social and emotional development which is very fundamental. Children's life nowadays touched with technology so they play also by using gadget. When children preoccupied with gadget, they will forget with their surrounding world because they feel comfortable to be alone by playing gadget, so they withdraw themselves from their environment. Childhood is the period of aspects development including social and emotional skill which is very fundamental.

The earlier study had proved that ICT usage can reduce the level of creativity among children. The mistake not lie merely on children, but all educators and parents. They should attentive to the way of selecting gadget, application and even the right duration for children. One of them is that social development in children occurs from birth and it is a process of imitation. A child who grow and develop should be involved directly in this process. The development of this social skill need learning process which take time and eyes contact when socializing is mental learning which is important for child's social and emotional development.

The negative effect invoked by gadget is child's social skill development [2]. Child will lack of interaction with environment, parents and peers. The habit of playing gadget in child will result in dependency behavior which can destruct child's social and emotional development. The individualist children cause them not care about their surrounding environment. So they lack of socialization in community. Whereas, this socialization process will be continued from childhood to adulthood. If children still stuck on technology sophistication, then they will be difficult to communicate with surrounding community.

Addictive behavior is triggered by preoccupation obtained when using gadget. One category of development in social acceptation is "isolate". A child is said as isolated when he/she doesn't have best friend among their peers. Addictive to gadget can reduce children activeness and their ability to interact with others. Children become less interactive and prefer to be alone with their comfort zone with gadget. It can result in individualistic attitude in children and they will less care about others whether their friend or someone else. According to Hurlock, that there are two kinds of isolate, namely (1) voluntary isolate is self withdraw from group because less interested to follow the activity of that group; (2) involuntary isolate is being rejected by group because his/her present is not needed [7].

Social acceptance behavior in children environment is very important to make children capable to self-adjust in their group. According to Hurlock [7], the criteria of social adjustment which should be possessed by a child are: (1) real appearance; if a child can fulfill the expectation of group and become member who is accepted in his/her group. (2) self-adjustment to various groups; if a child is able to self-adjust well in various groups existed in his/her environment; (3) social attitude; a child should be able to show pleasant attitude to other, participate socially and play role in his/her social group; (4) personal satisfaction; child feel satisfied with the role he/she play in group.

Some studies mentioned that gadget usage will result in problems including loneliness/depression, lack of impulse control, social comfort, and another disorders will invoke chronic effect for its users. Parents always give time discipline in order that stimulation needed by children to be success in social development can be fulfilled as the asset for the future.

THE INFLUENCE OF GADGET USAGE ON CHILDREN'S EMOTIONAL DEVELOPMENT 
Emotion is first learning window (Gani, 2016). Emotion comprise pleasure, comfort, fear, anxious which are fundamental for children. If children feel comfort with everything then they will continuously seek to get it. Attunement is the strongest emotional stimulation needed to brain development, which involve parents or another adult who respond correctly to children's emotional condition.

Attunement is very important in children's emotional development. The main time of emotional development of a child is found in the age under ten years old. In that time, brain take the series needed to experience and control basic emotions (Steward at al, 1985) from happy, angry, fear and sad, emphatic, and anxiety. It is the reason why it is better that baby and children not play with gadget. If face to face interaction with others in real time is very important for children's emotional development, and particularly if attunement is not fulfilled, then there will be serious consequence for children emphatic, moral and social growth, the parents' role is to be aware and understand of importance of this emotional development.

Emotion relate to mood, temperament, personality, disposition and motivation [8]. Motivation direct and give energy to behavior, whereas emotion give affective, motivation, positive and negative components. The related difference is between emotion and emotion result, particularly behavior and emotional expression. People often behave in certain manner as a direct result of their emotional situation, such as cry, fight and run away. If one can has emotion without suitable behavior, then we can consider that behavior is not important for emotion.

The phenomena in field shows that children who are addicted to gadget are more aggressive and less able to control emotion when they are felt disturbed and their gadget are out of order. A study mentioned that when children are preoccupied in playing gadget in predetermined time, when the time is over then they will ask additional time. It is one sign of addiction effect. Children with their power will hit, become aggressive, or cry. Addiction to gadget occurs because lack of parents' attention (diverted to gadget). Children tend to be closer to their gadget so they feel that they cannot be separated from gadget. Emotional disorder such as aggressive is a result of children are exposed to violence display in their gadget. Many videogames now display murder, raping, torture and violence contents.

The gadget usage excessively in children will result in addiction. Children are good imitator. They will do everything they see and hear. The criteria of addiction including preoccupation, less tolerate, lost of control, and self-withdrawal [9]. If it occurs continuously and excessively then children's emotional ability will be disturbed because what they will imitate what they see frequently in gadget. If the period of emotional development is hindered by the factors influence it, then children will have labile emotion which will continuously brought until their adulthood. According to the researchers before, gadget usage is one factor which can inhibit children's emotional development because of their emotion is less stimulated so children do not have stable emotion, because the emotional development itself is acquired when children interact with their environment.

PFC or Pre Frontal Cortex is the part inside the brain which control emotion, self control, responsibility, decision making and another moral values. In children who are addictive to technology such as games online, their brain will produce excessive dopamine hormone which make the PFC function is impaired and it make children become introvert. Their dependency on gadget make them consider that gadget is everything for them. They will be stress and anxious if they are taken apart from their gadget. Most of their time spent by playing with gadget. As a consequence, parent and children intimacy is reduced, and children also tend to become introvert.

\section{CONCLUSION}

Emotional development cannot be separated from social skill development. Because people live in environment with behavior and emotion which will be judged by their social life. Therefore, the success of social development in children will be strongly depend on their social development, because children will not acquire various kind of characters in social environment from gadget. Children will not be addicted to gadget if parenting and parents' role is prioritized for children development. Parents are demanded to play active role to supervise and control their children in using gadget so their development is not delayed because they use gadget excessively.

Parents should use smart parenting because it will strongly influence on child individual. Letting childrento use gadget for a long time or excessively will make them become addicted to gadget and it give negative effect to their emotional development and they will less understand social adjustment in environment because their lack of interaction.

\section{Suggestion}

Parents should be aware of the effect of gadget exposed to children which can influence their 
development. The following are the things that can be done by parents and caregivers:

1. Giving good example to children in using gadget responsibly.

2. Giving attunement or attention and response to children from birth.

3. Accompanying and not letting young children to play with gadget freely.

4. Parents should be assertive and wise in giving gadget to children aged under two years old.

5. Giving knowledge to children on how to use gadget responsibly.

\section{References}

[1] Fadzil, N. M., Abdullah, M. Y., Azul, M., \& Salleh, M. (2016). The Level Of Tolerance Sanctioning Children Using Gadgets By Parents Lead To Nomophobia : Early Age, 9(2), 615-622.

[2] Gani, S. A. (2016). Parenting Digital Natives: Cognitive, Emotional , and Social Developmental Challenges. Internasional Conference on Education, 870-880
[3] Dallea, Mutalibb, Saadb, Ayubc, Wahabc, and Nasrallad.(2015).Usability Considerations Make Digital Interactive Book Potential For Inculcating Interpersonal Skills. Jurnal Teknologi (Sciences \& Engineering) 77:2963 68 Volume 01,Issue 09 Pages 1495-1499

[4] Upadhyay, Jesudass and Chitale.(2014). Impact Of Electronic Gadgets.India. International Journal of Emerging Trends in Science and TechnologyVolume 01, Issue 09 Pages 14951499

[5] Bhattacharyya.(2015).Addiction To Modern Gadgets And Technologies Across Generations. India. Eastern Journal of Psychiatry Volume 18, Issue 2.

[6] Maier, Laumer and Weinert.(2013). The Negative Side Of IctEnabled Communication:The Case Of Social Interaction Overload In Online SocialNetworks. Germany. AIS Electronic Library (AISeL)

[7] Hurlock, Elizabeth B. (1978). Perkembangan Anak Jilid 1Edisi Ke Enam. Jakarta : Erlangga.

[8] Sl, M., Hanakeri, P. A., \& Aminabhavi, V. A. (2016). Impact of gadgets on emotional maturity , reasoning ability of college students, 2, 749-755.

[9] Kuss, D. J., \& Lopez-fernandez, O. (2016). World Journal of Psychiatry, 6(1), https://doi.org/10.5498/wjp.v6.i1.143 